University of Nebraska - Lincoln

DigitalCommons@University of Nebraska - Lincoln

Uniformed Services University of the Health

Sciences

U.S. Department of Defense

2011

\title{
Suicide in the United States Air Force: Risk factors communicated before and at death
}

\author{
Daniel W. Cox \\ Uniformed Services University of the Health Sciences \\ Marjan Ghahramanlou-Holloway \\ Uniformed Services University of the Health Sciences, mholloway@usuhs.mil \\ Farrah N. Greene \\ Uniformed Services University of the Health Sciences \\ Jennifer L. Bakalar \\ Uniformed Services University of the Health Sciences \\ Christina L. Schendel \\ Uniformed Services University of the Health Sciences \\ See next page for additional authors
}

Follow this and additional works at: https://digitalcommons.unl.edu/usuhs

Part of the Medicine and Health Sciences Commons

Cox, Daniel W.; Ghahramanlou-Holloway, Marjan; Greene, Farrah N.; Bakalar, Jennifer L.; Schendel, Christina L.; Nademin, M. Elicia; Jobes, David A.; Englert, David R.; and Kindt, Michael, "Suicide in the United States Air Force: Risk factors communicated before and at death" (2011). Uniformed Services University of the Health Sciences. 63.

https://digitalcommons.unl.edu/usuhs/63

This Article is brought to you for free and open access by the U.S. Department of Defense at DigitalCommons@University of Nebraska - Lincoln. It has been accepted for inclusion in Uniformed Services University of the Health Sciences by an authorized administrator of DigitalCommons@University of Nebraska Lincoln. 


\section{Authors}

Daniel W. Cox, Marjan Ghahramanlou-Holloway, Farrah N. Greene, Jennifer L. Bakalar, Christina L. Schendel, M. Elicia Nademin, David A. Jobes, David R. Englert, and Michael Kindt 
Research report

\title{
Suicide in the United States Air Force: Risk factors communicated before and

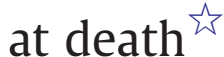

\author{
Daniel W. Cox ${ }^{\text {a }}$, Marjan Ghahramanlou-Holloway ${ }^{a, *}$, Farrah N. Greene a , Jennifer L. Bakalar ${ }^{\text {a }}$, \\ Christina L. Schendel ${ }^{\text {a }}$, M. Elicia Nademin ${ }^{\text {b}}$, David A. Jobes ${ }^{c}$, David R. Englert ${ }^{\text {d }}$, Michael Kindt ${ }^{e}$ \\ a Department of Medical and Clinical Psychology, Uniformed Services University of the Health Sciences, Bethesda, MD, USA \\ b Veteran's Administration and Private Practice, Phoenix, AZ, USA \\ ' Department of Psychology, The Catholic University of America, Washington, DC, USA \\ d United States Air Force Office of Special Investigations, Andrews AFB, MD, USA \\ e United States Air Force Suicide Prevention Program, Lackland AFB, TX, USA
}

\section{A R T I C L E I N F O}

\section{Article history:}

Received 31 December 2010

Received in revised form 15 April 2011

Accepted 9 May 2011

Available online 8 June 2011

\section{Keywords:}

Suicide

Suicide risk factor

Suicide note

Interpersonal

Military

Air force

\begin{abstract}
A B S T R A C T
Background: Over the last decade, suicide rates in the U.S. military have steadily increased, resulting in a call for suicide-related research with military populations. The present project aimed to describe and evaluate the communications (i.e., verbally and in suicide notes) of 13 suicide risk factors in the suicide death investigation files of 98 active duty U.S. Air Force (USAF) members.

Methods: Two-hundred thirty-seven suicide death investigation files were coded. Ninety-eight decedents left suicide notes and were included in the current analyses. Descriptive statistics were computed to evaluate the types of risk factors most commonly communicated prior to and at the time of death as well as the medium for their communication. Specifically, verbal and note communications were compared to evaluate which medium decedents most often used to communicate risk factors. Also, the frequency that interpersonal compared to intrapsychic risk factors were communicated was evaluated.

Results: Hopelessness (35.7\% of cases) and perceived burdensomeness (31.6\% of cases) were the risk factors most often communicated in suicide notes but not verbally. Thwarted belongingness ( $29.6 \%$ of cases) was the risk factor most often communicated verbally and in the suicide note. Further, evaluated risk factors were more frequently communicated in suicide notes than verbally. Finally, interpersonal risk factors were more often communicated than intrapsychic risk factors.

Limitations: The validity of the data relies on interviews of decedents' acquaintances and various medical/military records.

Conclusions: Our findings support emphasizing certain risk factors over others in USAF suicide prevention efforts. Further, interpersonal risk factors appeared to be more salient than intrapsychic risk factors in the minds of decedents.
\end{abstract}

(C) 2011 Elsevier B.V. All rights reserved.

\footnotetext{
Disclaimer: The opinions or assertions contained herein are the private views of the authors and are not to be construed as official or as reflecting the views of the Uniformed Services University of the Health Sciences, the Department of Defense, the United States Air Force, or the United States Air Force Office of Special Investigations.

* Corresponding author. Department of Medical \& Clinical Psychology, Uniformed Services University of the Health Sciences, 4301 Jones Bridge Road, Room B3050, Bethesda, MD 20814-4799, USA. Tel.: +1 301295 3271; fax: + 13012953034.

E-mail address: mholloway@usuhs.mil (M. Ghahramanlou-Holloway).
} 


\section{Introduction}

Suicide is the second leading cause of death, after accidents, among active duty U.S. military members (Center for Disease Control and Prevention, 2011). Rates per 100,000 for active duty members in the four branches in 2009 were: Marines, 24; Army, 21.7; Navy, 13.3; and Air Force, 12.5. These rates demonstrate a steady increase in military suicide over the past decade, across branches, and the highest rate for the U.S. Air Force since 2004 (USAF) (Department of Defense Task Force on the Prevention of Suicide by Members of the Armed Forces, 2010). Further, current and former military members represented approximately $18 \%$ to $20 \%$ of U.S. suicides from 2005 to 2007 (Center for Disease Control and Prevention, 2011). The increasing rate of suicide in the military resulted in a call for military-suicide research and prevention efforts with the hope that a better understanding of the precipitants of suicide among decedents would inform methods for early intervention and suicide prevention (Department of Defense Task Force on the Prevention of Suicide by Members of the Armed Forces, 2010).

Empirically determined risk factors guide identification of potential intervention points and contribute to theory. Rudd et al. (2006) identified the following warning signs as being associated with suicide risk: (a) hopelessness, (b) anger, (c) revenge, (d) social withdrawal, and (e) agitation. In a nationwide study of suicide in Finland; Heikkinen et al. (1994) reported several other suicide correlates: (a) job related problems, (b) family conflict, (c) physical illness, (d) financial difficulties, (e) unemployment, (f) separation, ( $g$ ) death of a close relative, and (h) family illness. Joiner et al. (2002) furthered the study of suicide predictors by suggesting that interpersonal distress (i.e., between at least two people) is a greater risk factor for suicide than intrapsychic distress (i.e., within the self; emotional).

Several studies have highlighted the significant role of interpersonal risk factors in suicide (Brown et al., 2002; Felthous, 1997; Joiner et al., 2009; Kaslow et al., 2002). In Joiner's interpersonal-psychological theory of suicidal behavior (hereafter referred to as the interpersonal theory), he emphasizes the role of interpersonal predictors of suicide, specifically perceived burdensomeness and thwarted belongingness (Joiner et al., 2009). In two studies evaluating risk factors communicated in suicide notes, perceived burdensomeness was the only risk factor that predicted (a) suicides compared to attempted suicides and (b) the lethality of attempt in a sample of decedents (Joiner et al., 2002). Intrapsychic risk factors that did not predict suicide or lethality of attempt included emotional pain, hopelessness, and using suicide as a method for controlling feelings. In another study with undergraduates, Van Orden et al. (2008) demonstrated that perceived burdensomeness and thwarted belongingness predicted suicide ideation above and beyond age, gender, and depressive symptoms. Similarly, Filiberti et al. (2001) analyzed psychological autopsies of cancer patients who died by suicide and found that feeling like a burden to others was one of the most influential factors in their suicides. Taken together, these findings support the interpersonal theory-interpersonal risk factors are more relevant to suicide death than intrapsychic risk factors.

Common methods for assessing psychological correlates of suicide include interviewing and giving self-report measures to people who recently attempted or ideated about suicide. These methods, while valuable, are limited in their utility because they cannot be used with suicide decedents (Leenaars, 2002). One method for assessing the experience of decedents is reviewing their suicide notes. Evaluating the content of suicide notes provides a personalized glance into the minds of decedents immediately before suicide (Frederick, 1969). Through suicide note research, psychological risk factorsexperienced by those who ended their lives-have been identified. In an article on the clinical implications of suicide note research, Leenaars (1991) identified several risk factors elucidated by the qualitative analyses of suicide notes. Although concerns have arisen about the limitations of suicide note research, the counterargument has been made that suicide is complex and multiple methods-all of which have limitations-should be employed to better understand the phenomenon.

Although many suicide risk factors are known, opportunities for intervention are often missed. In a study of primary care visits, Rodi et al. (2010) found that decedents-just prior to suicide-more often visited physicians and more often visited them for mental health reasons than non-suicidal matched controls. Rodi and colleagues' conclusion-that physicians often have the opportunity to intervene prior to suicide-was furthered by Cassels (2009) who argued that healthcare providers frequently miss opportunities for suicide prevention when patients visit emergency departments. In a study of patients admitted to an intensive care unit for a suicide attempt by tablet overdose, Wolk-Wasserman (1986) evaluated what patients who had attempted suicide communicated to their significant others just prior to the attempt and how their significant others responded. They concluded that even though patients frequently communicated their distress and significant others understood these communications, significant others most often responded with silence. Taken together, these findings demonstrate that those who contemplate suicide frequently communicate their distress to healthcare professionals or to other people in their lives before making a suicide attempt; however, opportunities for intervention are often missed.

U.S. military members experience unique barriers to behavioral healthcare that jeopardize opportunities for intervention. In an evaluation of service members deployed to Iraq or Afghanistan, Hoge et al. (2004) found that only half of those in need of behavioral healthcare received treatment. Further, stigma about this type of treatment was a major barrier to receiving care. In the military, many members fear that if they seek relational, behavioral, or spiritual counseling, they will be marginalized and stereotyped as weak or damaged. Recently, the Secretary of Defense commissioned a task force to examine the prevention of suicide in the military (Department of Defense Task Force on the Prevention of Suicide by Members of the Armed Forces, 2010). The task force found that the stigma of mental illness transcends military ranks and that there have been cases of discrimination and humiliation by superiors towards service members for seeking behavioral healthcare services. Similar findings have been reported in samples of civilian men. Approximately $85 \%$ of U.S. active duty military personnel are men (Statistical Information Analysis Division, 2010), and men have been found to underreport pain and attend fewer primary care and behavioral healthcare 
appointments (Bertakis et al., 2000; Unruh et al., 1999). Courtenay (2000) argued that men deny physical and emotional suffering as well as suppress emotional expression.

In response to the call to action for military suicide research and prevention (Department of Defense Task Force on the Prevention of Suicide by Members of the Armed Forces, 2010), we examined the suicide death investigation files of U.S. Air Force members (i.e., airmen) who died by suicide, to explore three major aims. The first aim was to describe the manner and frequency in which 13 risk factors (described below) were communicated. Specifically, we compared the verbal communications of the 13 risk factors that occurred within 30 days of the suicide to the suicide note communications of the same risk factors. The second major aim was to compare the frequency of verbal communications to the frequency of suicide note communications. We hypothesized that due to stigma, airmen would more often communicate the 13 risk factors in suicide notes rather than verbally. We further hypothesized that this same finding would persist when examining (a) only intrapsychic factors and (b) only interpersonal factors. We defined interpersonal risk factors as pertaining to relations between persons and intrapsychic risk factors as within the mind or self. The third major aim was to compare the frequency of interpersonal risk factors communicated to the frequency of intrapsychic risk factors communicated. We hypothesized that interpersonal risk factors would be more salient in the minds of decedents than intrapsychic risk factors across communication types and within suicide note communications. To test this we compared the frequency of communications of interpersonal risk factors to the frequency of communications of intrapsychic risk factors (a) across communication types (i.e. verbal and suicide note), (b) within verbal communications, and (c) within suicide note communications. Because of stigma associated with reporting emotional distress, we further hypothesized that airmen would not often verbally communicate interpersonal or intrapsychic risk factors, thus there would be no significant differences between groups when examining verbal communications.

\section{Methods}

\subsection{Sample}

The sample in our parent study consisted of 237 suicide death investigation files of airmen who died by suicide from 1996 to 2006. All of the available files from 2000 to 2006 were coded, resulting in 219 of the 258 (85\%) USAF suicides during those seven years. Files from 1996 to 1999 were randomly selected because they were part of a different project that used the same coding form (Nademin et al., 2008). Of the 237 airmen who died by suicide, 98 (41\%) left a suicide note. Only those who left suicide notes were included in the current project. We defined a suicide note as a hand-written or typed note left at the scene of the suicide. The following characteristics summarize our sample: mean age at the time of suicide was 29.65 years $(S D=8.46$, range $=19-56)$; 85 (86.7\%) were male; 80 (81.6\%) were White, 10 (10.2\%) were Black or African American, 3 (3.1\%) were Asian, 3 (3.1\%) were Hispanic/Latino, 2 (2\%) were unknown; 49 (50\%) were married, 14 (14.3\%) were divorced, 34 (34.7\%) were never married, 1 (1\%) had an unknown marital status; and regarding military rank 43
(43.9\%) were E1 to E4, 41 (41.8\%) were E5 to E9, 14 (14.3\%) were officers, and 1 (1\%) had an unknown rank. Psychiatric diagnostic information was available for only a subset of the suicide decedents because many did not have the opportunity to be diagnosed prior to death. Among those diagnosed, frequency of diagnosed disorders (some of which co-occurred) follows: 10 (10.2\%) Major Depressive or Dysthymic Disorder, 6 (6.1\%) Adjustment Disorder, 5 (5.1\%) Alcohol Abuse or Dependence Disorder, 3 (3.1\%) Bipolar Disorder, 1 (1.0\%) Post Traumatic Stress Disorder, 1 (1.0\%) Attention-Deficit/ Hyperactivity Disorder, 1 (1.0\%) Dependent Personality Disorder, and 1 (1.0\%) Narcissistic Personality Disorder.

\subsection{Data collection}

Following every active duty airman's suicide, the U.S. Air Force Office of Special Investigations (AFOSI) conducts a comprehensive suicide death investigation of the decedent for the major purposes of determining the manner of death and ruling out foul play. Investigations are used to describe the personality of the decedent and the circumstances surrounding the suicide (Young, 1992). The files included: (a) interviews conducted by the AFOSI staff with persons known to the deceased (e.g., family, friends, coworkers); (b) relevant records such as personnel, medical, mental health, and financial; (c) toxicology and medical autopsy reports; and (d) evidence from the death scene (e.g., suicide notes).

\subsection{Data extraction}

Our research team coded suicide death investigation files using a Microsoft Access electronic coding form developed by experts in suicidology ${ }^{1}$ and modified by the second author of this manuscript. The form contains 453 variables. Coders had a minimum of a bachelor's degree and were trained on procedures for finding and extracting information from suicide death investigation files and on issues of confidentiality. Further, coders utilized a coding manual that operationalized the coding for each variable. Verbal and suicide note communications of risk factors were dichotomously coded as either yes (present) or no (absent). For verbal communications, risk factors had to have been communicated within 30 days of the suicide for it to be coded as present. This information was extracted from interviews by AFOSI investigators or medical records. For suicide note communications, coders determined the presence or absence of risk factors by reading the suicide notes. In the coding manual, the 13 risk factors were defined as: (a) agitation - restlessness, upset, irritation, sense of urgency, increased physiological psychomotor activity; (b) anger communication of anger; (c) hopelessness - lack of hope for the future; (d) loneliness - feelings of being alone; (e) loss of job satisfaction - losing a sense of satisfaction in the workplace; (f) loss of status - lost military rank or other occupational status; (g) missed friends - longing for friends once had; (h) perceived burdensomeness - feeling that others would be better off without them; (i) rejection - abandonment, neglect,

\footnotetext{
1 Developers of the coding form included David Jobes; Thomas Joiner; Barry Wagner; David Rudd; M. Elicia Nademin; Air Force Suicide Prevention Program Manager, Col Rick Campise; and AFOSI Chief, Behavioral Analysis Division, Maj David Englert.
} 
or rejection; ( $\mathrm{j}$ ) revenge - resentment or want for vengeance; (k) shame - feeling disgraced or embarrassed; (1) self hate hatred toward self; ( $\mathrm{m}$ ) thwarted belongingness - incapacity to obtain or perceive sense of belonging or feeling of rejection subsequent to efforts toward connectedness. A random sampling procedure was used to select $10 \%$ of coded cases for evaluating inter-rater reliability. Reliability was high across coded variables with kappa coefficients ranging from 0.6 to 1.0, as previously reported (Nademin et al., 2008). Institutional review board permission was obtained for the study.

\subsection{Data analyses}

The first analyses were conducted to describe how frequently decedents' communications of the 13 risk factors fell into the following four communication categories-(a) verbally and in the suicide note, (b) only verbally, (c) only in the suicide note, and (d) not communicated. Crosstabs were computed for each risk factor with communicated in the suicide note as the row variable and communicated verbally as the column variable. The two communication categories of greatest interest were (a) verbally and in the suicide note and (b) only in the suicide note. We conceptualized risk factors communicated verbally and in suicide notes as unresolved because decedents communicated the risk factor prior to suicide, yet the risk factor was again communicated in the suicide note, indicating that it was not resolved. We conceptualized risk factors communicated only in suicide notes as hidden because they were of concern to the decedent, yet appeared to be undisclosed to others prior to suicide.

As noted above, each decedent was dichotomously coded (present or absent) for each risk factor. To compare the number of risk factors communicated verbally to the number communicated in suicide notes, we summed the dichotomous responses (e.g., if a decedent communicated hopelessness and agitation in their suicide note and no other risk factor, we classified the decedent as having communicated two risk factors in the note). Then, we conducted a pairedsamples $t$ test between verbal and suicide note communications to evaluate differences on the number of risk factors communicated. We conducted these same analyses within (a) intrapsychic risk factors and (b) interpersonal risk factors. In our final set of analyses we categorized 8 of the original 13 risk factors as interpersonal (i.e., perceived burdensomeness, thwarted belongingness, rejection, and revenge) or intrapsychic (i.e., agitation, hopelessness, loss of job satisfaction, and self hate) based on previous literature (e.g., Joiner et al., 2002) and our own judgment. To compare interpersonal and intrapsychic communications, we summed the original dichotomous coding in the same way as for the previous analysis. For our first hypothesis-interpersonal risk factors would be more frequently communicated than intrapsychic risk factors across communication types-we summed the eight intrapsychic and interpersonal risk factors within verbal communications and within note communications (resulting in a possible range of scores from zero to eight). For our second and third hypotheses-(a) within verbal communications, there would be no differences in the frequency of intrapsychic compared to interpersonal communications and (b) within suicide note communications, interpersonal risk factors would be more frequently communicated than intra- psychic risk factors-we summed the four interpersonal risk factors and the four intrapsychic risk factors within verbal communications and within note communications (resulting in a possible range of scores from zero to four). Then, we conducted paired-samples $t$ tests between interpersonal and intrapsychic risk factors to evaluate differences on the number of risk factors communicated.

All data were analyzed using SPSS 17.0.

\section{Results}

\subsection{Frequency of the four communication styles}

Crosstabs were computed for each of the 13 risk factors to demonstrate how frequently decedents communicated in the four communication categories (see Table 1). The four communication categories and the risk factor most frequently communicated in that category were: (a) verbally and in the suicide note, thwarted belongingness; (b) only verbally, loss of job satisfaction; (c) only in the suicide note, hopelessness; and (d) not communicated, missed friends.

\subsection{Note communications compared to verbal communications}

To test the hypothesis that the 13 risk factors were more frequently communicated in suicide notes than in verbal communications, a paired-samples $t$ test was conducted (see Table 2). Results indicated that the mean number of risk factors communicated in suicide notes $(M=3.73, S D=2.88)$ was significantly greater than the mean number of verbal communications $(M=2.38, S D=2.46), t(97)=4.20, p<.001$, $d=0.43,95 \% \mathrm{CI}[0.72,2.00]$.

To test the hypothesis that intrapsychic and interpersonal risk factors were communicated more frequently in suicide notes than verbally, paired samples $t$ tests were conducted. Results indicated that the mean number of intrapsychic risk factors communicated in suicide notes $(M=1.19, S D=1.09)$ was significantly greater than the mean number of intrapsychic risk factors communicated verbally $(M=0.74$, $S D=0.93), t(97)=3.62, p<.001, d=0.37,95 \%$ CI $[0.70$, 0.20]. Further, the mean number of interpersonal risk factors communicated in suicide notes $(M=1.44, S D=1.20)$ was significantly greater than the mean number of interpersonal risk factors communicated verbally $(M=0.84, S D=1.05), t$ $(97)=5.12, p<.001, d=0.52,95 \% \mathrm{CI}[0.03,-0.70]$.

\subsection{Interpersonal compared to intrapsychic risk factors}

To test the hypothesis that across communication types, interpersonal risk factors were more frequently communicated than intrapsychic risk factors, a paired-samples $t$ test was conducted (see Table 3 ). Results indicated that the mean number of interpersonal risk factors $(M=2.27, S D=1.92)$ were not significantly different than the mean number of intrapsychic risk factors across communication types $(M=1.95, S D=1.61), t(97)=0.09, p=0.09, d=0.17,95 \%$ CI [-0.05, 0.68].

To test the hypothesis that within verbal communications there would be no differences in the frequency of interpersonal compared to intrapsychic risk factors, a paired-samples $t$ test was conducted. Results indicated that the mean number 
Table 1

Frequency of themes in the four communication categories.

\begin{tabular}{|c|c|c|}
\hline Theme & $\begin{array}{l}\text { Communicated in the suicide note } \\
\mathrm{n}(\%)\end{array}$ & $\begin{array}{l}\text { Not communicated in the suicide note } \\
\mathrm{n}(\%)\end{array}$ \\
\hline \multicolumn{3}{|l|}{ Agitation } \\
\hline Communicated verbally & $11(11.2 \%)$ & $13(13.3 \%)$ \\
\hline Not communicated verbally & $18(18.4 \%)$ & $56(57.1 \%)$ \\
\hline \multicolumn{3}{|l|}{ Anger } \\
\hline Communicated verbally & $14(14.3 \%)$ & $9(9.2 \%)$ \\
\hline Not communicated verbally & $12(12.2 \%)$ & $63(64.3 \%)$ \\
\hline \multicolumn{3}{|l|}{ Hopelessness } \\
\hline Communicated verbally & $19(19.4 \%)$ & $3(3.1 \%)$ \\
\hline Not communicated verbally & $35(35.7 \%)^{c}$ & $41(41.8 \%)$ \\
\hline \multicolumn{3}{|l|}{ Loneliness } \\
\hline Communicated verbally & $14(14.3 \%)$ & $13(13.3 \%)$ \\
\hline Not communicated verbally & $16(16.3 \%)$ & $55(56.1 \%)$ \\
\hline \multicolumn{3}{|l|}{ Loss of job satisfaction } \\
\hline Communicated verbally & $6(6.1 \%)$ & $15(15.3 \%)^{b}$ \\
\hline Not communicated verbally & $5(5.1 \%)$ & $72(73.5 \%)$ \\
\hline \multicolumn{3}{|l|}{ Loss of status } \\
\hline Communicated verbally & $6(6.1 \%)$ & $8(8.2 \%)$ \\
\hline Not communicated verbally & $9(9.2 \%)$ & $75(76.5 \%)$ \\
\hline \multicolumn{3}{|l|}{ Missed friends } \\
\hline Communicated verbally & $0(0.0 \%)$ & $2(2.0 \%)$ \\
\hline Not communicated verbally & $6(6.1 \%)$ & $90(91.8 \%)^{\mathrm{d}}$ \\
\hline \multicolumn{3}{|l|}{ Perceived burdensomeness } \\
\hline Communicated verbally & $9(9.2 \%)$ & $3(3.1 \%)$ \\
\hline Not communicated verbally & $31(31.6 \%)$ & $55(56.1 \%)$ \\
\hline \multicolumn{3}{|l|}{ Rejection } \\
\hline Communicated verbally & $22(22.4 \%)$ & $8(8.2 \%)$ \\
\hline Not communicated verbally & $20(20.4 \%)$ & $48(49.0 \%)$ \\
\hline \multicolumn{3}{|l|}{ Revenge } \\
\hline Communicated verbally & $4(4.1 \%)$ & $4(4.1 \%)$ \\
\hline Not communicated verbally & $10(10.2 \%)$ & $80(81.6 \%)$ \\
\hline \multicolumn{3}{|l|}{ Shame } \\
\hline Communicated verbally & $7(7.1 \%)$ & $5(5.1 \%)$ \\
\hline Not communicated verbally & $24(24.5 \%)$ & $62(63.3 \%)$ \\
\hline \multicolumn{3}{|l|}{ Self hate } \\
\hline Communicated verbally & $4(4.1 \%)$ & $2(2.0 \%)$ \\
\hline Not communicated verbally & $20(20.4 \%)$ & $72(73.5 \%)$ \\
\hline \multicolumn{3}{|l|}{ Thwarted belongingness } \\
\hline Communicated verbally & $29(29.6 \%)^{a}$ & $3(3.1 \%)$ \\
\hline Not communicated verbally & $15(15.3 \%)$ & $51(52.0 \%)$ \\
\hline
\end{tabular}

abcd Themes most frequently communicated in their respective categories.

of interpersonal risk factors verbally communicated $(M=0.84, S D=1.05)$ did not significantly differ from the mean number of intrapsychic risk factors verbally communicated $(M=0.74, S D=0.93), t(97)=0.92, p=0.36, d=0.09$, $95 \% \mathrm{CI}[-0.11,0.29]$.

To test the hypothesis that within suicide note communications, interpersonal risk factors would be more frequently communicated than intrapsychic risk factors, a paired-samples $t$ test was conducted. Results indicated that the mean number of interpersonal risk factors communicated within suicide notes $(M=1.44, S D=1.20)$ were significantly greater than the mean number of intrapsychic risk factors communicated in suicide notes $(M=1.19, S D=1.09), t(97)=2.09, p=0.04$, $d=0.21,95 \% \mathrm{CI}[-0.11,0.29]$.

\section{Discussion}

Examining the suicide death investigation files of airmenspecifically records of verbal communications 30 days prior to suicide and suicide notes-revealed the frequency with which 13 suicide-related risk factors fell into four communication types: (a) verbal communication only, (b) note communication only,

Table 2

Differences in frequency between verbal and suicide note communications $(N=98)$.

\begin{tabular}{|c|c|c|c|c|c|}
\hline \multirow[t]{2}{*}{ Risk factors } & \multicolumn{2}{|c|}{ Verbal communications } & \multicolumn{2}{|c|}{ Suicide note communications } & \multirow[t]{2}{*}{$t(97)$} \\
\hline & $M$ & $S D$ & $M$ & $S D$ & \\
\hline Intrapsychic and interpersonal & 2.36 & 2.46 & 3.73 & 2.88 & $-4.20^{* * *}$ \\
\hline Intrapsychic & 0.74 & 0.93 & 1.19 & 1.09 & $-3.62^{* * *}$ \\
\hline Interpersonal & 0.84 & 1.05 & 1.44 & 1.20 & $-5.12^{* * *}$ \\
\hline
\end{tabular}

\footnotetext{
$* * * \mathrm{p}<.001$.
} 
Table 3

Differences in frequency of types of themes communicated between interpersonal and intrapsychic themes $(N=98)$.

\begin{tabular}{|c|c|c|c|c|c|}
\hline \multirow[t]{2}{*}{ Communication medium } & \multicolumn{2}{|c|}{ Interpersonal themes } & \multicolumn{2}{|c|}{ Intrapsychic themes } & \multirow[t]{2}{*}{$t(97)$} \\
\hline & $M$ & $S D$ & $M$ & $S D$ & \\
\hline Verbal and suicide note & 2.27 & 1.92 & 1.95 & 1.61 & 1.73 \\
\hline Verbal communications & 0.84 & 1.05 & 0.74 & 0.93 & 0.92 \\
\hline Suicide note communications & 1.44 & 1.20 & 1.19 & 1.09 & $2.09^{*}$ \\
\hline
\end{tabular}

${ }^{*} \mathrm{p}<.05$

(c) verbal and note communication, or (d) not communicated. Note communication only and verbal and note communication were the communication types of greatest interest. We conceptualized risk factors that were communicated in the suicide note but not verbally as being hidden from others. Hopelessness (35.7\% of cases) and perceived burdensomeness (31.6\% of cases)-two of the strongest predictors of suicide (McMillan et al., 2007; Van Orden et al., 2008)-were the risk factors most often hidden by decedents. We conceptualized risk factors that were verbally communicated and communicated in the suicide note as unresolved and missed opportunities for intervention. These risk factors were communicated prior to suicide-indicating that there was an opportunity for intervention-and they were communicated in the suicide notesuggesting that the risk factor was never resolved. Thwarted belongingness was the most often occurring risk factor $(29.6 \%$ of cases) communicated verbally and in the suicide note, followed by rejection (22.4\% of cases).

These hidden and unresolved risk factors inform assessment and intervention. Given that our sample is part of an organization-the USAF-efforts that target the entire organization can be implemented. For example, building on the finding by Rodi et al. (2010) that primary care visits are common just prior to suicide, primary care physicians could routinely screen for suicide risk factors. Further, after deployment, military service members complete a postdeployment assessment (Wright et al., 2002). This questionnaire contains items that directly inquire about suicide. The usefulness of this measure may be enhanced if specific risk factors-such as hopelessness and thwarted belongingnessare assessed. Currently, the USAF trains all its members in suicide prevention and has more advanced trainings for frontline supervisors who work in the most at risk career fields (see http://www.af.mil/suicideprevention.asp) (U.S. Air Force, 2011). Examples of these trainings include the Applied Suicide Intervention Skills Training (ASIST) and the ACE (ask, care, escort) model for intervention. We encourage USAF trainings to specifically attend to interpersonal risk factors as our findings demonstrate their prevalence in the minds of decedents before suicide.

Our finding-airmen expressed more risk factors in suicide notes than verbally-supports previous arguments that service members do not express their mental health concerns (Hoge et al., 2004). The Department of Defense and the U.S. Congress have been working to change the perceptions of mental illness in the military (Department of Defense Task Force on the Prevention of Suicide by Members of the Armed Forces, 2010). Several recommendations have been made for reducing stigma associated with support-seeking and expanding the understanding of normal reactions to combat and military life. One specific recommendation was minimiz- ing the disclosure of mental health history required for security clearances. The infamous question 21 of the Questionnaire for National Security Positions has been rewritten in recent years to only require the disclosure of psychotherapeutic treatment if it was for violence or if it was court mandated (Jelinek, 2008). Such efforts may reduce stigma surrounding mental health concerns and increase the willingness of service members to seek treatment.

Consistent with the interpersonal theory (Van Orden et al., 2010), which posits that interpersonal stressors are the strongest risk factors for suicidal desire, decedents in our sample expressed more interpersonal risk factors than intrapsychic risk factors in their suicide notes. As expected, this difference was not observed in reports of verbal communication prior to death, bolstering previous conclusions that decedents withhold information from others about salient stressors that contributed to their decision to end their lives (Levi et al., 2008). These findings provide support for the salience of interpersonal concerns in the lives of USAF suicide decedents prior to death.

\subsection{Limitations and future directions}

Our study had several limitations that encourage future research. First, retrospective studies, such as analyzing suicide death investigation files, have several drawbacks (Hess, 2004). Primarily, researchers must depend on previously collected information. Valuable data could be absent or erroneously documented due to omissions by investigators or sources (e.g. interviewees or medical records). However, as noted, retrospective analysis is the primary method used to obtain information about suicide decedents-thus is often the best available method for constructing prevention efforts (Foster, 2003; Gadit, 2007; Leenaars, 1991; McClelland et al., 2000). A second limitation is that we chose risk factors prior to coding the suicide death investigation files. Although their inclusion was based on the scientific literature, other risk factors that were communicated may not have been coded because they were not included on the coding form. Future research using inductive methods would allow greater freedom to assess risk factors without a priori variable selection, allowing for greater access into the subjective experience of decedents. Third, although our selection of interpersonal and intrapsychic variables was based on previous research, it was subjective. Further, there is overlap between these two domains. As previously noted regarding perceived burdensomeness, although it is "rooted in interpersonal experience, [it] is also an intrapersonal belief" (Joiner et al., 2002). Fourth, this study only examined decedents who left a suicide notes. These decedents may be qualitatively different from those who do not leave notes. For example, it is 
possible that those who leave suicide notes-compared to those who do not-experience greater interpersonal distress and want to communicate that distress. Of course, the true reasons for suicide-regardless of the presence or the absence of suicide notes-cannot be fully deciphered posthumously. Research examining differences between decedents who left notes compared to decedents who did not was inconclusive, with some studies finding differences in the suicide methods (Salib et al., 2002; Tuckman et al., 1959) and others finding demographic differences (Heim and Lester, 1990). Preliminary analyses of our sample suggested that only gender significantly differed between decedents who left notes and those who did not; thus, our findings cannot be definitively generalized to decedents who do not leave notes. Future research efforts examining the differences in risk factors between those who leave notes and those who do not would be valuable. A final limitation of the present study is that results gleaned from our USAF sample do not necessarily represent other military or civilian populations. As noted above, military members and men in general $(86.7 \%$ of our sample) experience barriers to expressing mental health concerns; for our findings to be generalizable, further research must be conducted with other populations (Bertakis et al., 2000; Hoge et al., 2004; Unruh et al., 1999).

Despite the aforementioned limitations, this project had numerous strengths. First, we used a sample from the U.S. military, a population at increasing risk for suicide but understudied in the suicide literature. Further, these airmen died by suicide-a population that is rarely studied due to difficulties attaining retrospective data. Another strength was the depth and breadth of the data collected. As noted above, using suicide death investigation files has several limitations; however, the files evaluated for the present study were quite thorough-typically containing hundreds of pages-due to investigators having access to information (e.g. medical and military records) that researchers often do not. Finally, we examined verbal and suicide note communications. To our knowledge, this is the first study to compare these two communication mediums, which allowed several evaluations that have never before been conducted.

\section{Role of funding source}

Funding for this study was provided under a new faculty startup package provided to Dr. Ghahramanlou-Holloway by the Department of Defense, Uniformed Services University of the Health Sciences, Bethesda, Maryland.

\section{Conflict of interest}

Dr. Ghahramanlou-Holloway is employed by the Uniformed Services University of the Health Sciences. Maj Englert and Lt Col Kindt are members of the United States Air Force. Dr. Cox, Dr. Greene, and Dr. Schendel are contractors employed by the Henry M. Jackson Foundation for the Advancement of Military Medicine, Inc. through funding awarded to Dr. Ghahramanlou-Holloway by the Department of Defense. No other authors have any potential conflicts of interest.

\section{Acknowledgments}

The authors would like to thank (1) the Air Force Office of Special Investigation's staff for their support on record retrieval and review and (2) the study coders (Kathryn DeYoung, Elisabeth Fritz, Brianne George, Samuel Golenbock, Kristen Kochanski, Kathryn Lou, Rachael Lunt, Jeffery Martin, Melinda Moore, Aviella Snitman, Graham Sterling, Edwin Szeto, and MK Yeargin) for their assistance with data collection.

\section{References}

Bertakis, K., Azari, R., Helms, L., Callahan, E., Robbins, J., 2000. Gender differences in the utilization of health care services. J. Fam. Pract. 49, 147-152.

Brown, G.K., Henriques, G.R., Ratto, C., Beck, A.T., 2002. Cognitive Therapy Treatment Manual for Suicide Attempters. University of Pennsylvania, Philadelphia.

Cassels, C., 2009. APA 2009: Young Women Veterans at High Risk for Suicide [Online]. San FranciscoAvailable at: http://www.medscape.com/ viewarticle/7034242009accessed June 172010.

Center for Disease Control and Prevention, 2011. Web-based Injury Statistics Query and Reporting System (WISQARS) [Online]Available at: http:// www.cdc.gov/injury/wisqars/index.html 2011 accessed Jan 32011.

Courtenay, W., 2000. Constructions of masculinity and their influence on men's well-being: a theory of gender and health. Soc. Sci. Med. 50, 1385-1401.

Department of Defense Task Force on the Prevention of Suicide by Members of the Armed Forces, 2010. The Challenge and the Promise: Strengthening the Force. Preventing Suicide and Saving Lives, Washington, DC.

Felthous, A.R., 1997. Does "isolation" cause jail suicides? J. Am. Acad. Psychiatry Law 25, 285-294.

Filiberti, A., Ripamonti, C., Totis, A., Ventafridda, V., De Conno, F., Contiero, P., Tamburini, M., 2001. Characteristics of terminal cancer patients who committed suicide during a home palliative care program. J. Pain Symptom Manage. 22, 544-553.

Foster, T., 2003. Suicide note themes and suicide prevention. Int. J. Psychiatry Med. 33, 323-331.

Frederick, C.J., 1969. Suicide notes: a survey and evaluation. Bull. Suicidol. $17-26$.

Gadit, A.A., 2007. The suicide note: what can be done in the light of its implications? J. Pak. Med. Assoc. 57, 327-328.

Heikkinen, M., Aro, H., Lonnqvist, J., 1994. Recent life events, social support and suicide. Acta Psychiatr. Scand. Suppl. 377, 65-72.

Heim, N., Lester, D., 1990. Do suicides who write notes differ from those who do not? A study of suicides in West Berlin. Acta Psychiatr. Scand. 82, 372-373.

Hess, D.R., 2004. Retrospective studies and chart reviews. Respir. Care 49, 1171-1174.

Hoge, C.W., Castro, C.A., Messer, S.C., McGurk, D., Cotting, D.I., Koffman, R.L., 2004. Combat duty in Iraq and Afghanistan, mental health problems, and barriers to care. N. Engl. J. Med. 351, 13-22.

Jelinek, P., 2008. Security clearance Question 21 rewritten [Online]. Army TimesAvailable at: http://www.armytimes.com/news/2008/04/ ap_clearancescreening_043008/ 2008 accessed December 30th 2010.

Joiner, T., Pettit, J., Walker, R., Voelz, Z., Cruz, J., Rudd, M., Lester, D., 2002. Perceived burdensomeness and suicidality: two studies on the suicide notes of those attempting and those completing suicide. J. Soc. Clin. Psychol. 21, 531-546.

Joiner Jr., T.E., Van Orden, K.A., Witte, T.K., Rudd, M.D., 2009. The Interpersonal Theory of Suicide: Guidance for Working with Suicidal Clients. American Psychological Association, Washington, DC, US.

Kaslow, N.J., Thompson, M.P., Okun, A., Price, A., Young, S., Bender, M., Wyckoff, S., Twomey, H., Goldin, J., Parker, R., 2002. Risk and protective factors for suicidal behavior in abused African American women. J. Consult. Clin. Psychol. 70, 311-319.

Leenaars, A.A., 1991. Suicide notes and their implications for intervention. Crisis 12, 1-20.

Leenaars, A.A., 2002. In defense of the idiographic approach: studies of suicide notes and personal documents. Arch. Suicide Res. 6, 19-30.

Levi, Y., Horesh, N., Fischel, T., Treves, I., Or, E., Apter, A., 2008. Mental pain and its communication in medically serious suicide attempts: an “impossible situation”. J. Affect. Disord. 111, 244-250.

McClelland, L., Reicher, S., Booth, N., 2000. A last defence: the negotiation of blame within suicide notes. J. Community Appl. Soc. 10, 225-240.

McMillan, D., Gilbody, S., Beresford, E., Neilly, L., 2007. Can we predict suicide and non-fatal self-harm with the Beck Hopelessness Scale? A metaanalysis. Psychol. Med. 37, 769-778.

Nademin, E., Jobes, D.A., Pflanz, S.E., Jacoby, A.M., Ghahramanlou-Holloway, M., Campise, R., Joiner, T., Wagner, B.M., Johnson, L., 2008. An investigation of interpersonal-psychological variables in air force suicides: a controlled-comparison study. Arch. Suicide Res. 12, 309-326.

Rodi, P.M., Roskar, S., Marusic, A., 2010. Suicide victims' last contact with the primary care physician: report from Slovenia. Int. J. Soc. Psychiatry 56, 280-287.

Rudd, M.D., Berman, A.L., Joiner Jr., T.E., Nock, M.K., Silverman, M.M., Mandrusiak, M., Van Orden, K., Witte, T., 2006. Warning signs for suicide: theory, research, and clinical applications. Suicide Life. Threat. Behav. 36, 255-262. 
Salib, E., Cawley, S., Healy, R., 2002. The significance of suicide notes in the elderly. Aging Ment. Health 6, 186-190.

Statistical Information Analysis Division, 2010. Military Personnel Statistics [Online]Available at: http://siadapp.dmdc.osd.mil/personnel/MILITARY/ miltop.htm2010 accessed December 30th 2010.

Tuckman, J., Kleiner, R.J., Lavell, M., 1959. Emotional content of suicide notes. Am. J. Psychiatry 116, 59-63.

U.S. Air Force, 2011. AF.mil-Suicide Prevention [Online]Available at: http:// www.af.mil/suicideprevention.asp 2011 accessed Apr 82011.

Unruh, A.M., Ritchie, J., Merskey, H., 1999. Does gender affect appraisal of pain and pain coping strategies? Clin. J. Pain 15, 31-40

Van Orden, K., Witte, T., Gordon, K., Bender, T., Joiner Jr., T., 2008. Suicidal desire and the capability for suicide: tests of the interpersonal- psychological theory of suicidal behavior among adults. J. Consult. Clin. Psychol. 76, 72-83.

Van Orden, K.A., Witte, T.K., Cukrowicz, K.C., Braithwaite, S.R., Selby, E.A., Joiner Jr., T.E., 2010. The interpersonal theory of suicide. Psychol. Rev. $117,575-600$.

Wolk-Wasserman, D., 1986. Suicidal communication of persons attempting suicide and responses of significant others. Acta Psychiatr. Scand. 73, 481-499.

Wright, K.M., Huffman, A.H., Adler, A.B., Castro, C.A., 2002. Psychological screening program overview. Mil. Med. 167, 853-861.

Young, T.J., 1992. Procedures and problems in conducting a psychological autopsy. Int. J. Offender Ther. 36, 43-52. 